\title{
An Analysis of the Current Situation of Employment Under the Impact of COVID-19 and Its Countermeasures -- Based on the Survey of Qingdao City
}

\author{
Gao Xin ${ }^{1, a}$, Han Bingxuan ${ }^{1}$, Cong Kaiyuan ${ }^{1}$, Jiang Chunlei ${ }^{1}$, Dou Liwen ${ }^{1, b^{*}}$ \\ ${ }^{1}$ Shandong University of Traditional Chinese Medicine, Jinan 250355 China \\ a2522896858@qq.com \\ b*douliwen@163.com
}

\begin{abstract}
Novel coronavirus pneumonia outbreak in early 2020 and the employment problem of people are further expanding. Therefore, it is particularly important to investigate and study the problems of people in various aspects of employment when the epidemic occurs. This paper selects key counties and towns in Qingdao for discussion and research by using four investigation and research methods: literature research method, observation method, interview method and questionnaire method. This paper analyzes and discusses the transformation of people's employment concept, various employment modes under the current epidemic, the employment situation under the epidemic, the impact of the epidemic on enterprise recruitment and the national employment policy implemented in the epidemic, summarizes the employment structure system of Qingdao in the epidemic, and discusses the transformation of people's employment concept and mode in the epidemic. This paper clearly points out the employment problem that people are eager to solve in the epidemic situation, and puts forward the procedure and structural system of employment under the epidemic situation.
\end{abstract}

Keywords: COVID-19, obtain employment, Qingdao

\section{安国利民，攻克时艰：新冠疫情冲击下就业形势的现 状分析及对策研究——基于青岛市的调查}

高金韩 1 秉璇 1 从开源 ${ }^{1}$ 江春蕾 1 窦立雯 $1, \mathrm{~b}^{*}$

${ }^{1}$ 山东中医药大学, 山东济南, 中国 250355

a2522896858@qq.com

b*douliwen@163.com

\section{摘要}

2020 年初新冠肺炎疫情暴发，人民就业问题进一步扩大，因此对于疫情下人民在就业时各个方面出现的问题 进行调查和研究显得尤为重要。本文运用文献研究法、观察法、访谈法、调查问卷法四种调查研究方法, 选取 青岛市重点县镇进行探讨研究。从人民就业观念的转变、当今疫情下多种就业方式、疫情下的就业形势、疫情 对于企业招聘工作的影响和疫情中实施的国家就业政策等方面进行分析讨论，总结了疫情中青岛的就业结构 体系,并依此讨论了疫情中就业人民就业观念及方式的转变。文章明确指出了在疫情中人民急于解决的就业问 题,并提出了疫情下就业的程序与结构体系。

关键词: 新冠疫情, 就业，青岛 


\section{1.引言}

民生无小事，枝叶总关情。新冠疫情之下，人民 就业问题牵动着十数亿中华儿女的心, 给就业和劳动 力人才市场带来了严重的冲击, 人民服务社会奉献社 会的宗旨也无法得到全面实现。疫情使人们无法正常 见面, 人员不能正常流通, 企业难以正常运转, 资金 流通陷入半停顿状态。所有的工作人员都面临着严峻 的挑战, 尤其是运输乘务行业、服务行业、旅游行业, 就业岗位都大量减少。所以疫情中“失业易, 就业难” 的问题已经成为不争的事实。就业与民生息息相关, 深入剖析新冠疫情对于就业的影响, 并提出具有针对 性的建议与对策就显得尤为迫切和重要 ${ }^{\left[{ }^{1}\right.}$ 。

\section{1 研究背景}

随着 2015 年一带一路的开展, 就业问题得到一 定解决, 但是 2020 年新冠疫情的爆发, 使已经缓和 的问题又一次变得严峻, 宏观经济指标以及就业市场 各项指标走势均不理想, 其中, GDP 下降 $6.8 \%$, 城 镇调查失业率从 1 月份的 $5.3 \%$ 陡升至 2 月份的 $6.2 \%$, 3 月份仍维持在 $5.9 \%$ 的高位水平。从就业市场的需求 方面来看, 用人单位受到疫情的直接影响。可见, 在新 冠疫情影响下, 用人单位提供的就业岗位有所下降,人 民就业市场需求严重低于供给,人民面临的就业形势 十分严峻。[2]

\section{2 研究现状}

\subsection{1 国内研究现状}

目前国内的疫情总趋势趋于稳定, 较完善的就业 体系使得疫情不会对就业产生过大的影响。基于 29 个典型城市在几大招聘网站的每日新增招聘岗位数 据, 2020 年 1 月 28 日的招聘数量仅为 2019 年 12 月 6 日的 $13 \%$ 。在疫情得到有效控制之后，招聘数量持 续攀升, 3 月 20 日当日样本招聘数量已达到了 2019 年 12 月 6 日的 $93 \%$ 。虽然疫情对于就业的冲击已经 有了降低的趋势, 不再产生更多有害影响, 但是仍要 加强在疫情中对于就业体系的完善。

2020 年 7 月 21 日, 习近平总书记在企业家座谈 会上指出 “当前就业压力加大, 部分劳动者面临失业 风险”。做好“六稳”, 落实“六保”, 首先就是要稳就业、 保就业。做好了就业工作, 才能保民生, 从而保障我 国经济安全运行 0 。

\subsection{2 国际研究现状}

随着新冠疫情在全球的不断蔓延, 其对就业的影 响也不断扩大, 涉及全球大部分国家, 发达经济体的 美国和作为新兴经济体的印度的失业率为 $25 \%$, 而在 非洲等一些欠发达地区, 占就业人口大多数的非正规 就业者的失业率远超 25\%。日本的失业率在疫情暴发 后出现上升, 但即使到 2020 年 10 月份失业率最高的
时候也只有 $3.1 \%$, 只比 2019 年同期高了 0.7 个百分 点。韩国的失业率在疫情暴发后也出现上升, 但到 2020 年 5 月份失业率最高时只有 $4.5 \%[5]$, 之后失业 率就开始进入下降轨道。具体情况如图 (见图 1) 所 示。

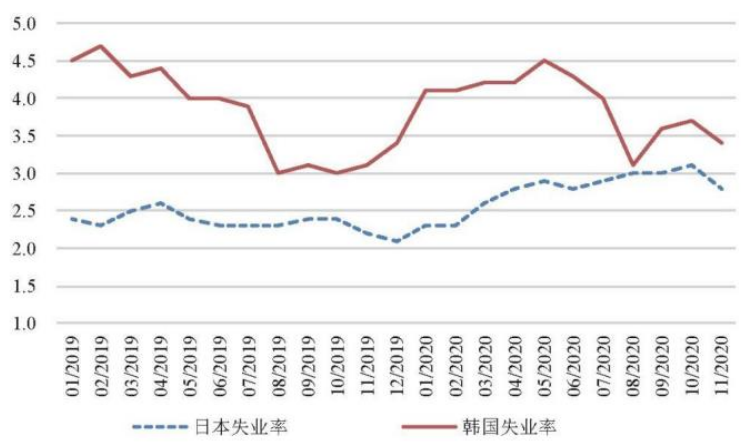

图 1 2019-2021 年日本与韩国失业率变化

面对疫情下人民就业困难这一局面, 美国提供就 业保障专项贷款，用以纾解中小微企业资金困难，美 国中小企业管理局 (SBA) 创设薪酬保障计划 (Paycheck Protection Program, 以下简称 PPP)。PPP 贷款是面向中小微企业, 主要用于员工薪资支持, 并 可获得一定额度豁免的贷款。SBA 还针对中小企业实 施了贷款减免政策，即对疫情前发放、由 SBA 担保 的部分中小企业贷款, SBA 将自动代偿 6 个月本金、 利息和相关手续费 0 。这一政策解决了疫情中失业人 员的生活问题，同时也给中小型企业一次在疫情中喘 息的机会, 其精准的指向性使疫情下美国的就业并未 受到毁灭性的打击。

“短时工作制”作为德国应对 2008 年经济危机的 一项重要举措成为缓解就业压力、渡过危机的首选。 如今“短时工作制”也依然可以用来应对疫情环境下 的就业问题。该举措通过减少员工工作时间, 并按照 员工实际的工作量支付少量工资，而不足原工资的部 分，由德国联邦劳工局补偿这部分工资（税后金额） 的 $60 \%$ 。“短时工作制”的实施不仅解决了企业在疫情 中资金不足的问题，较大程度上也解决了疫情中人民 就业的问题。

\section{2.新冠疫情防控下的就业情况}

\section{1 新冠疫情防控下的就业形势}

新冠疫情防控下的就业形势不容乐观。受新冠疫 情影响, 就业市场呈现出供过于求趋势, 此次疫情的 爆发, 使得企业停工停产增多, 用工需求下降, 就业 人数下降, 失业率明显上升。与此同时, 疫情期间企 业招聘活动减少, 市场就业机会不足, 例如, 大批应 届毕业生找不到合适的工作，处于暂时失业状态; 一 部分人就业意愿下降, 丧失工作能力或不愿工作, 就 业率骤降。 
目前我国的疫情已经基本得到控制, 但国际疫情 持续蔓延以及国内疫情不确定因素, 使我国进入后疫 情时代, 经济下行压力和后疫情时代的双重叠加, 无 疑对解决就业问题提出了更高的要求, 要想真正扭转 就业形势严峻局面，需要政府、市场、企业、高校等 多方面做出努力，转“危”为“机”。

\section{2 新冠疫情防控下新型就业政策}

新冠疫情爆发后, 迅速推出《关于应对新冠肺炎 疫情影响强化稳就业举措的实施意见》(国办发 $(2020)$ 6 号)、《关于应对新冠肺炎疫情做好 2020 届全国普 通高等学校毕业生就业创业工作的通知》、《关于应对 新冠肺炎疫情影响做好事业单位公开招聘高校毕业 生工作的通知》等一系列针对疫情中就业的就业政策, 一定程度上缓解了人民就业困难的问题。如此深远而 又详细的民生政策可以看出国家和党对人民就业的 重视程度之高。

\section{3 新冠疫情防控下就业模式}

新冠疫情的袭来, 带来的不仅是就业形势的严峻, 更是就业模式的转变。随着疫情防控下就业形势的改 变, 单纯依靠传统正规就业已经不能适应我国的基本 国情, 非正规就业将成为未来就业的必然选择, 我国 就业模式将会经历一个由正规化向非正规化的转变。 例如疫情期间, 涌现出了许多新兴的线上职业, 将线 上就业与线下就业相结合，打破了传统的就业模式， 缓解了疫情防控下就业形势的紧张局面, 提高了就业 率，提升了人民幸福生活指数。

\section{3. 研究结果及分析}

\section{1 调查的目的与意义}

通过对大学生以及社会人士的问卷调查和对青 岛市具有代表性的中小型企业的实地调研, 可窥探疫 情中当代人民对于就业观念的转变、就业方式的变换 以及企业对于劳动力的需求和招聘方式的改变。

通过对疫情中人们就业观念的转变和方式变化 的分析, 深度剖析疫情下我国的就业形势, 通过对于 就业形势的解析, 从更深处认识到疫情中人民在就业 时所遇到的困难和存在的问题。

\section{2 疫情中对于青岛市人民就业的分析}

\subsection{1 青岛市现实就业情况分析}

2020 年以来, 青岛市人力资源和社会保障局稳定 全市就业形势, 截至 11 月底, 新增就业 44.55 万人, 同 2019 年比增长 $18.86 \%$, 城镇登记失业率 3.02\%; 为全市经济社会发展提供坚强人才支撑, 吸引双一流 高校毕业生 3316 名,预计全年引进聚集各类人才 25 万人; 为 2.5 万名劳动者追回各类经济损失 3.2 亿元,
12333 民生服务热线人工接听受理 84.3 万件。青岛市 荣获中国年度最佳“引才城市”和“促进就业城市”。

实施政策落实行动、实施援企稳岗行动、实施创 业扶持行动、实施就业帮扶行动, 这“四大行动”的实 施, 不仅稳定扩大了青岛市就业, 还确保就业形势的 稳定。并且针对于疫情下的就业形势, 改革创新便企 利民的“五项举措”，创新解决企业复工复产用工难问 题、创新人社政策“云课堂”宣讲品牌、创新打造智慧 社保经办服务体系、创新推动胶东五市人社服务一体 化、创新开展便捷高效的人社云服务, 这“五项举措” 为人民在疫情中就业提供优质高效政务服务。

\subsection{2 疫情中青岛市就业形势的变化}

我们对青岛市进行线上结合线下问卷调查, 问卷 参与人数 600 人，调查问卷的有效率为 $93 \%$ 。各地区 大学生及社会人士通过填写调查问卷, 真实地反映了 自己对于疫情下就业形势的感受。

(1) 在新冠疫情的影响下, 大学生对自身当前专 业的就业前景的自我感觉分析

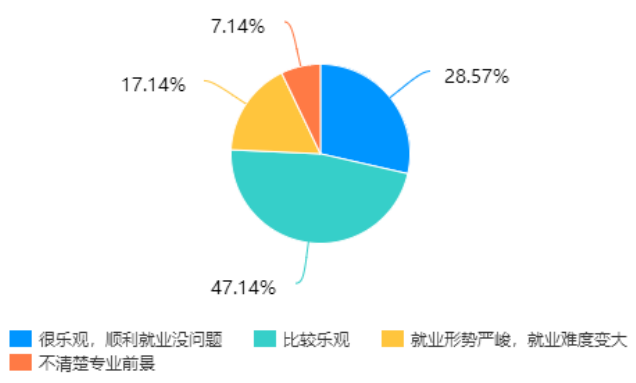

图 2 大学生针对就业的不同心态占比

根据图表（见图 2）显示, 有 $47.14 \%$ 的大学生认 为专业前景比较乐观, $28.57 \%$ 的大学生认为很乐观, 顺利就业没问题，由此可以看出，疫情之下，大部分 大学生对于自身的专业还是有较高的信任程度, 不会 过于迷茫。

（2）对于疫情下大学生的对于就业的态度研究

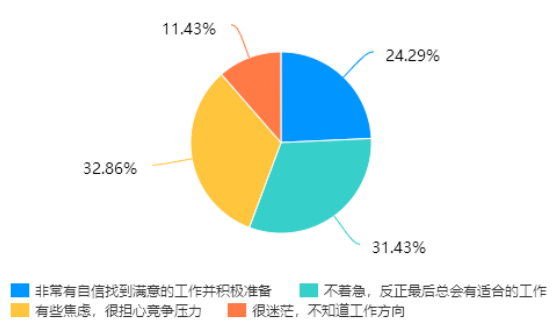

图 3 大学生针对就业的态度占比

根据图表（见图 3) 显示，32.86\%的大学生感觉 自己可以找到满意的工作，并且积极准备，31.43\%的 大学生就业态度不够积极。根据以上两条的结合, 可 以看出疫情下的大学生对于自身的就业分为两种派 别, 一种是积极奋斗, 有较详细的未来规划, 对于自 
身能力有较高的肯定; 另一种是安于现状, 对于未来 的自我规划还没有构建。

(3) 对疫情下大学生对就业观的偏向的分析 (多 选）

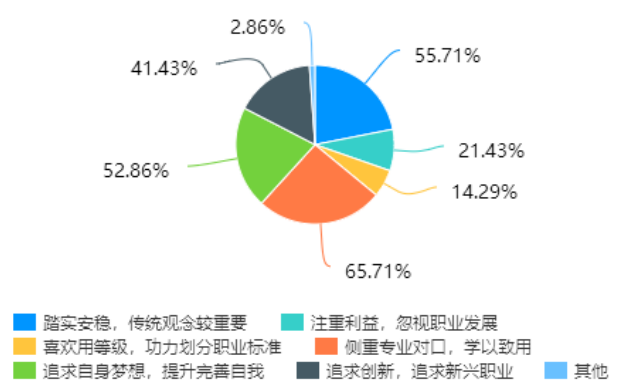

图 4 大学生不同就业观占比

根据上图（见图 4) 可知, $65.71 \%$ 的大学生偏向 于侧重专业对口, $55.71 \%$ 的大学生偏向于踏实安稳, 传统观念, $52.86 \%$ 和 $41.43 \%$ 的大学生偏向于追求自 身梦想和追求创新。通过对于这些数据的研究不难发 现, 大学生对于就业观偏向无非分为两个方面, 一是 传统意义上的较稳定的工作，俗称“铁饭碗”，另一种 则是无论是国家还是各大高校都在大力支持的创新 创业。

（4）对于后疫情时代大学生选择职业时会优先 考虑哪些因素的分析 (多选)

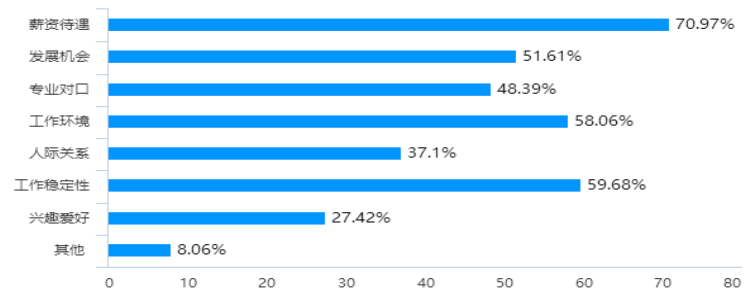

图 5 后疫情时代大学生考虑就业因素占比

由上表（见图 5) 可知, 大学生对于薪资待遇的 看重程度高达 $70.97 \%$, 远超其余各项; 位于第二阶梯 的工作稳定性、工作环境和发展机会也均超过 $50 \%$ 。 由此可见, 薪资待遇、工作稳定性、工作环境和发展 机会四点成为后疫情时代大学生就业的重要因素。

(5)对于后疫情时代, 大学生对于就业地点的选 择的分析

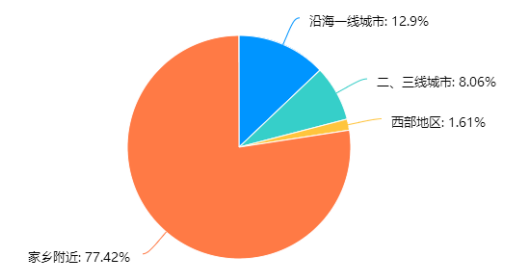

图 6 大学生倾向就业地点占比

由上图 (见图 6) 可以看出, 有 $77.42 \%$ 的大学生 选择在家乡附近就业, 选择在沿海就业的有 $12.9 \%$,
而对于二、三线城市和西部地区的选择只占 $8.06 \%$ 和 $1.61 \%$ 。从十分鲜明的占比差距可以看出大学生偏重 于回家乡就业, 而回家乡就业其实也就意味着想要获 得一份安定稳定的工作; 而还有一部分大学生选择一 线城市, 这一选择在较大程度上反映出这一部分人想 要追求高薪优待工作的心理。

（6）对疫情期之下社会人士偏向的工作种类进 行分析

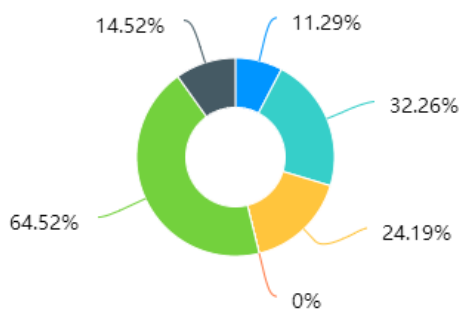

去西部或农村支教去机关单位整理信息目主创业，助力“地猚文化 加入目媒体，当一名正能量网红选择适合自己一技之长的工作

图 7 被调查人员对各种工作类型的选择情况

由上图可以发现（见图 7)，有 $64.52 \%$ 的社会人 士会选择适合自己一技之长的工作，有 $32.26 \%$ 的会 选择去机关单位从事相关工作, $24.19 \%$ 的会自主创业, 促进社会创新创业。

通过对这些数据的分析, 不难看出, 在疫情之下 大部分社会人士还是比较在意是否可以在工作中将 自己的才华完全体现，所从事的工作是否是自身价值 的体现; 一部分人会选择较平稳的类似于机关单位的 工作岗位，虽然薪资不会太高，但是福利待遇好，也 是社会人士选择其的重要因素; 还有一部分会加入国 家推广的大众创业。

（7）对疫情之下社会人士偏向的就业观的分析

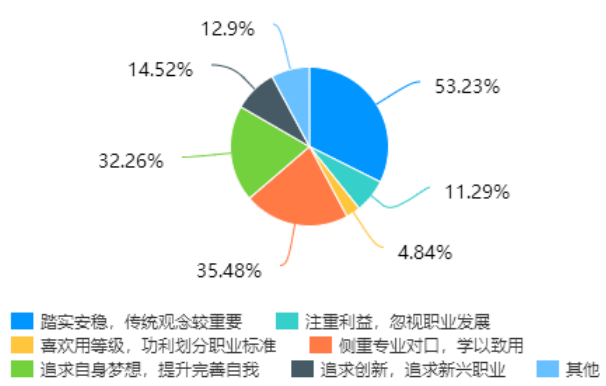

图 8 被调查人员的就业观念

对上图进行分析 (见图 8), 53.23\%的社会人士偏 向于踏实安稳, 认为传统观念较重要; $35.48 \%$ 侧重于 专业对口，学以致用; $32.26 \%$ 选择追求梦想，提升完 善自我的就业观。这一些数据的体现可以发现, 在这 些社会人士当中已经有一部分人开始追求自身的梦 想, 不再是刻板的追求安稳, 这说明在社会人士中, 就业观已经开始发生转变, 但是总体和大学生的就业 观念偏向相似。 


\section{2 .3 青岛市就业形势发展规划}

青岛市人力资源和社会保障局发布《疫情影响下 我市人力资源市场新变化的研究探索》, 据报告显示, 2020 年前三季度, 我市人力资源市场发布的岗位需求 总数为 31.4 万, 同比下降 $1 \%$, 受到疫情形势变化影 响，总体呈现两头高、中间低的“V”形结构。其前期 的下降主要是由于疫情的突然发生对就业市场产生 的不可避免的冲击, 后期的上升则是因为国家和青岛 市政府对于疫情中就业有所重视, 发布并实施有利于 疫情中人民就业的政策, 以及企业招聘体质的改革和 公共服务体系的优化。

\subsubsection{1 政府政策支持}

青岛市为响应国家发布的有关于稳就业政策的 号召, 青岛市人力资源和社会保障局、青岛市发展和 改革委员会等部门联合发布《应对疫情稳就业政策实 施细则》, 从“补、延、扩”三方面对稳就业政策进行细 化。

除以上政策外，青岛市还发布了《关于做好新型 冠状病毒感染肺炎疫情防控期间复工企业劳动用工 服务的通知》、青岛市人力资源和社会保障局等四部 门发布《关于转发人社部发(2020)8 号文件做好我 市新型冠状病毒感染肺炎疫情防控期间稳定劳动关 系支持企业复工复产的通知》等有关疫情中稳就业的 政策。

\subsubsection{2 企业招聘改革}

疫情中招聘准备阶段, 企业努力筹备资金, 在保 障企业可以正常运转的前提下, 保证职员工工资可以 正常发放; 增加就业方式, 通过尽可能不接触的新招 聘方式进行招聘; 在工位、人才功能设定上, 进一步 细化, 让求职者完全了解工作任务。

在招聘实施阶段, 努力满足求职者的需求, 不怕 耗时耗力, 选择真实可信的招聘平台, 及时发布岗位 信息, 线上认真篮查。通过“云”招聘等新招聘模式, 与求职者线上“面对面”的面试，使企业的招聘和求职 者的就业都可以得到顺利进行。

\subsubsection{3 公共服务优化}

青岛市将充分运用“互联网+”和“标准+”思维模 式，建成“互联网+就业创业”、“标准+就业创业”服务 体系, 搭建灵活就业服务平台, 支持灵活就业, 方便群 众就近就业、灵活就业。完善“一网两库三平台”建设, 推进互联网办理深度，服务事项网上办结率达到 $80 \%$ 以上。打造公共就业服务“标准+”青岛模式, 实现同城 通办。

\section{4. 疫情中就业问题的对策与建议}

通过对在这次新冠疫情中人民就业观念和就业 方式的深度剖析, 进一步了解后疫情时代的就业形势, 来发现在疫情中就业所存在的问题并针对这些问题 提出对策及建议。

\section{1 对策}

1.及时调整经济政策，缓解严峻就业形势;

2.妥善安排失业人群, 建立城镇就业“蓄水池”;

3.提高就业、失业保险政策的精准度, 强化失业 保险的保障生活功能;

\section{2 建议}

结合对人民对于就业政策的偏向、疫情发展的趋 势和就业市场的现状的观察，提出以下几点建议:

1. 建议对受到疫情影响的特定行业和企业进行 定向政策扶持, 减轻相关企业负担, 增加其经营韧性;

2.在疫情防控措施有效的前提下，希望允许相关 企业尽早复工增产, 并探索新型的员工招聘和管理方 式;

3. 建议加大就业困难群体的转移支付力度和职 业培训, 缓解相关群体初次和再就业难题, 保障相关 群体的基本生活水平;

4. 建议在本次疫情联防联控统一部署的基础上, 探索标准化而不失多样化的企业复工和人员流动管 控新机制。

\section{5.结语}

稳定的就业市场是经济发展的源头, 是社会稳定 的重要推动力。就业是最大的民生问题, 与每个人息 息相关, 一个人就业, 就可以安定, 一个家庭就业就 利于社会稳定。所以保住就业才能兒住民生底线, 保 住就业才能稳住经济基本盘。为促进疫情期间更好的 稳就业, 保就业, 政府给予特定的行业和企业相关政 策支持并开展新兴的员工招聘和管理方式对疫情下 经济快速增长至关重要。因此政府、企业、人民应共 同发力, 充分运用“互联网+”和“标准+”思维模式，共 同渡过疫情下这一短暂的经济增长压力。只有着手抓 好了就业, 百姓生活得以保障了才能更好地促进社会 发展。

\section{REFERENCES}

[1] Hou WZ.(2020)Employment Difficulties and Countermeasures under the influence of COVID-19 [J].Chinese Business Theory,No.821(22):28-30.

[2] Sun JY, Liu FY, Zhou YT, Wang RL.(2021)Analysis of the employment of college students under the 
background of the epidemic: the current situation, dilemma and countermeasures [J].Chinese Theory of Business,(19): 182-185.

[3] Zhu YK.(2020)Stable employment and guaranteed employment to promote the domestic big cycle [N].China Business Journal, No.001.

[4] Hou Y.(2020)Study on Youth Employment in the Background of Employment Protection [J].Chinese Youth Studies,(9).

[5] Liu XL,Song BN. ( 2021)Unemployment, unemployment correction, and employment security under the COVID-19 outbreak [J].Journal of China College of Labor Relations, 35 (04): 87-96.

[6] Ji BG, Zhang L. (2020) Experience and policies of countries to support employment during the epidemic period [J].Financial Vertical, No.506(09):40-45. 